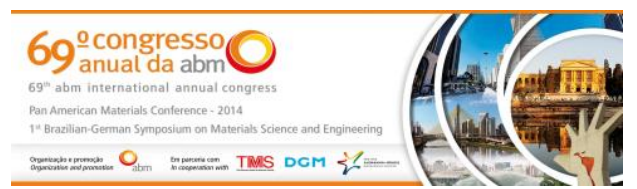

Tema: Metalurgia física e comportamento de materiais em temperaturas elevadas

\title{
EVOLUÇÃO DA MICROESTRUTURA E TEXTURA DO AÇO INOX FERRÍTIÇO ESTABILIZADO COM Nb APÓS LAMINAÇÃO A FRIO E RECOZIMENTO*
}

\author{
Izabela Vieira Teixeira Neves ${ }^{1}$ \\ Carolina Damasceno Netto de Matos ${ }^{1}$ \\ Alessandra Cunha Ferreira ${ }^{1}$ \\ Dagoberto Brandão Santos ${ }^{2}$ \\ Diana Perez Escobar ${ }^{3}$
}

\section{Resumo}

Os aços inoxidáveis ferríticos estabilizados com nióbio apresentam grãos mais refinados e uma recristalização mais homogênea quando comparados aos não estabilizados. Contudo, em seu processamento industrial, mais especificamente na laminação a quente, utiliza-se um recozimento antes da etapa de laminação a frio e do recozimento final, visando a homogeneização da microestrutura de entrada. Objetivando a melhoria das propriedades de estampagem e soldagem em aços com adição de $\mathrm{Nb}$, bem como uma possível redução de custos com a eliminação do recozimento após a laminação a quente, foram realizados testes com o aço inoxidável 430 estabilizado com Nb de forma a acompanhar a evolução de sua microestrutura e textura após ser submetido à laminação a frio com $80 \%$ de redução e recozimento a tempo constante (900 s) e diferentes temperaturas, $400^{\circ} \mathrm{C}$ a $1.000^{\circ} \mathrm{C}$, partindo-se de ambas condições iniciais. A quantificação da recristalização foi feita através da fração amaciada em função da temperatura, obtida pela curva de microdureza Vickers. A interpretação da textura foi obtida por exames por microscopia eletrônica de varredura e difração de elétrons retroespalhados (EBSD). Para o encharque de $900 \mathrm{~s}$, a recristalização se inicia a $700^{\circ} \mathrm{C}$. A $750^{\circ} \mathrm{C}$ o aço se encontra completamente recristalizado, alcançando um tamanho de grão da ordem de $8,0 \mu \mathrm{m}$. Os resultados mostram que o aço não recozido após a laminação a quente apresentou grãos mais refinados e ligeiramente menores. Além disso, notou-se o aumento da fibra gama e redução da fibra alfa em ambas as condições de processamento à medida que a recristalização progredia.

Palavras-chave: Aço inoxidável ferrítico; Laminação a frio; Recristalização; Difração de elétrons.

\section{MICROSTRUCTURE AND TEXTURE EVOLUTION OF FERRITIC STAINLESS STEEL STABILIZED WITH NIOBIUM AFTER COLD ROLLING AND ANNEALING PROCESS}

\begin{abstract}
Ferritic stainless steels stabilized with $\mathrm{Nb}$ have grains more refined and a recrystallization process more homogeneous if compared with those steels which are not stabilized. However, in its industrial processing, specifically in the hot rolling and annealing steps, it is usual to have an intermediate annealing treatment before cold rolling stage, in order to get a more homogeneous microstructure. Aiming to optimize the stamping and welding properties in steels with $\mathrm{Nb}$, and considering a costcutting due to the elimination of the intermediary annealing process, the ferritic stainless steel ASTM 430 stabilized with $\mathrm{Nb}$ was subjected to hot and cold rolling and annealing to compare the evolution of its microstructure and texture after thermo and mechanical processing with $80 \%$ thickness reduction and an isochronal annealing $\left(900 \mathrm{~s}\right.$ ) but at different temperatures (from $400^{\circ} \mathrm{C}$ to $1,000^{\circ} \mathrm{C}$ ). The recrystallizing volume fraction was obtained from the softened volume fraction as function of annealing temperature and from Vickers microhardness tests. Texture interpretation was made by scanning electron microscopy and electron back-scattering diffraction (EBSD). For a soaking time of $900 \mathrm{~s}$, the recrystallization begins at $700^{\circ} \mathrm{C}$. At $750^{\circ} \mathrm{C}$ the material is found completely recrystallized, reaching a grain size of about $8,0 \mu \mathrm{m}$. The results show that the non-annealed steel has more refined and slightly smaller grains. Furthermore, it was found the increase of $\gamma$-fiber and the reduction of $\alpha$-fiber in both of the process conditions as far as the recrystallization advanced.
\end{abstract}

Keywords: Ferritic stainless steel; Cold rolling; Recrystallization; EBSD.

1 Graduanda em Engenharia Metalúrgica, Departamento de Engenharia Metalúrgica e de Materiais, UFMG, Belo Horizonte, MG, Brasil.

2 Professor Associado, Dr., Depto. de Engenharia Metalúrgica e de Materiais, UFMG, Belo Horizonte, MG, Brasil.

3 Pós-doutoranda, PPGEM, CAPES, Departamento de Engenharia Metalúrgica e de Materiais, UFMG, Belo Horizonte, MG, Brasil.

\footnotetext{
* Contribuição técnica ao 69ํ Congresso Anual da ABM - Internacional e ao 14ํㅡㄹ ENEMET - Encontro Nacional de Estudantes de Engenharia Metalúrgica, de Materiais e de Minas, 21 a 25 de julho de 2014, São Paulo, SP, Brasil.
} 


\section{INTRODUÇÃO}

Os aços inoxidáveis se caracterizam por apresentarem um alto teor de cromo, acima de $10,5 \%$, o que proporciona uma maior resistência à corrosão. O aumento do preço do níquel no mercado mundial [1-3], juntamente com o alto custo referente à utilização dos aços austeníticos em algumas aplicações, provocou um interesse particular nos aços inoxidáveis ferríticos, já que esses não possuem níquel em sua composição e apresentam uma boa combinação de propriedades mecânicas e de resistência à corrosão. Além disso, essas propriedades mecânicas são mais significativas nestes aços quando comparadas aos aços carbono.

Tais propriedades podem ser aumentadas ou melhoradas a partir de diferentes tratamentos químicos e térmicos. Um exemplo de modificação das propriedades do material é o acréscimo de $\mathrm{Nb}$ à estrutura dos aços ferríticos, possibilitando que os mesmos tenham maior homogeneidade e refinamento em sua microestrutura em função do aumento dos locais de nucleação da ferrita [2], do grau de estampabilidade e soldabilidade e auxiliando no controle da textura cristalográfica destes aços. Essas características se devem, segundo a literatura, pela precipitação fina de $\mathrm{Nb}(\mathrm{C}, \mathrm{N})$ e que inibe a recristalização do material durante a laminação a quente [4]. Por seu turno, a presença destas partículas grosseiras, com um tamanho médio superior a $1 \mu \mathrm{m}$, favorece a nucleação dos grãos de ferrita durante a recristalização [5], facilitando os mecanismos de rearranjo de deslocações e formando regiões livres de defeitos associados a contornos de alto ângulo [5-7]. Assim, é gerada uma bobina LF que resultará em estruturas mais refinadas e grãos homogêneos após o processo de recozimento do aço sob influência do elemento $\mathrm{Nb}$.

É importante ressaltar também que o aumento de resistência à corrosão dos aços estabilizados ao $\mathrm{Nb}$ se dá pela oxidação do $\mathrm{Nb}$ em preferência a $\mathrm{Cr}$ existente na matriz do aço, uma vez que este é uma liga Fe-Cr que se desgasta quando ocorre a formação de óxido de cromo. Com essas inúmeras vantagens, é usual o acréscimo de $\mathrm{Nb}$ na fabricação do aço inoxidável AISI 430 ferrítico, amplamente utilizado na fabricação de utensílios e pias de cozinha, ornamentos automotivos, baixelas e maquinário para indústrias de açúcar e álcool, representando cerca de $13 \%$ de toda a produção de aços inoxidáveis ferríticos do mercado [3].

Um dos parâmetros que auxiliam na análise das características anteriormente citadas é a textura cristalográfica, já que o comportamento mecânico de materiais policristalinos, como é o caso do aço 430, é afetado consideravelmente pela textura do material [7-9]. Esta pode ser modificada por diferentes tratamentos térmicos e possibilita a caracterização do aço e a determinação de sua funcionalidade, o que é de grande importância para a aplicação e incorporação do material no mercado. Sabe-se, ainda, que a orientação preferencial dos grãos ideal para o aço inox estabilizado com $\mathrm{Nb}$ seria uma maior fração volumétrica de fibra $\gamma(\{111\} / / \mathrm{DN}))$, principal textura cristalográfica na melhoria da estampabilidade, e uma menor intensidade da fibra Teta $(\{100\} / / D N))[10,11]$, que é a principal componente de textura que tem como característica reduzir a estampabilidade do aço inoxidável.

Sendo assim, o presente trabalho teve como objetivo analisar o efeito do recozimento entre os processos de laminação a quente e a frio, denominado nesse trabalho como recozimento intermediário, de amostras de aço 430 estabilizado com $\mathrm{Nb}$, cedidas pela empresa produtora, a fim de comparar os efeitos dos diferentes tratamentos térmicos em relação à sua evolução microestrutural. As amostras foram analisadas após recozimentos isócronos em diferentes temperaturas, para

\footnotetext{
* Contribuição técnica ao $69^{\circ}$ Congresso Anual da ABM - Internacional e ao 14ํㅡㄹ ENEMET - Encontro Nacional de Estudantes de Engenharia Metalúrgica, de Materiais e de Minas, 21 a 25 de julho de 2014, São Paulo, SP, Brasil.
} 


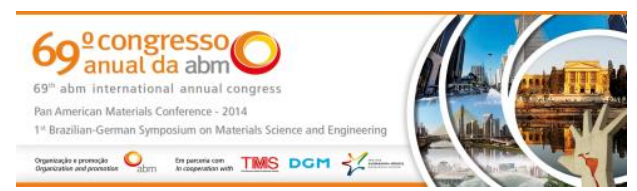

possibilitar a comparação do desenvolvimento dos grãos ferríticos na matriz do aço à medida que a temperatura de recozimento aumentava. Para efeito de comparação entre os aços que sofrem recozimento intermediário entre as deformações e aqueles que são recozidos apenas após o processo de laminação a frio, foram realizados testes de microdureza Vickers, permitindo a análise da recristalização dos aços, e microscopia óptica e eletrônica de varredura, além dos exames por difração de elétrons retroespalhados (EBSD), auxiliando nas conclusões em relação à orientação cristalográfica nestes aços, a sua textura.

\section{MATERIAIS E MÉTODOS}

Os aços fornecidos pela empresa eram amostras de aço inoxidável ferrítico 430E com e sem recozimento após o processo de laminação a quente, disponível em forma de chapas. A composição química é a seguinte: 0,02\%C; 0,20\%Mn; 0,03\%P; $0,32 \% \mathrm{Nb} ; 16,07 \% \mathrm{Cr} ; 0,18 \% \mathrm{Ni} ; 0,002 \% \mathrm{Al} ; 0,004 \% \mathrm{Ti} ; 0,0005 \% \mathrm{~S}$ e $0,024 \% \mathrm{~N}_{2}$. Em laboratório, houve o processo de laminação a frio, com redução de $80 \%$ em um Laminador Fröhling (40 t de capacidade, cilindros de diâmetro igual a $200 \mathrm{~mm}$ e comprimento igual a $300 \mathrm{~mm}$, instrumentado com células de cargas de compressão, com interfaces $A / D$ e computadorizado). Posteriormente, foram cortadas tiras de 1,0 $\mathrm{cm}$ de largura para os recozimentos Cada tira foi recozida em temperaturas, variando de $400 \mathrm{a} 1000^{\circ} \mathrm{C}$, com intervalos de $100^{\circ} \mathrm{C}$ até a temperatura de $600^{\circ} \mathrm{C} \mathrm{e}$, a partir de $600^{\circ} \mathrm{C}$, diminuindo-se os intervalos para $50^{\circ} \mathrm{C}$. Tal procedimento foi executado em um tempo de 15 min de encharque por amostra.

Após o recozimento, as tiras foram cortadas em dois pedaços (utilizando a máquina de corte com disco adiamantado "Allied" trabalhando em baixa rotação), os quais foram embutidos a quente, totalizando doze amostras do aço $430 \mathrm{E}$ não recozidas. As amostras embutidas em baquelita com pó de cobre foram lixadas em lixas d'água de granulometria de 240 até 1000 \#, para posterior polimento em politrizes manuais, utilizando pasta de diamantes de $9 \mu \mathrm{m}, 3 \mu \mathrm{m}$ e $1 \mu \mathrm{m}$. Para a realização exames via microscopia óptica o aço foi atacado com reativo de Vilella, colocando as amostras em imersão por, em média, $90 \mathrm{~s}$ cada. Já para a realização dos exames no MEV (Microscopia Eletrônica de Varredura), foi feito o polimento em politrizes manuais com pasta de diamante $9 \mu \mathrm{m}, 3 \mu \mathrm{m}, 1 \mu \mathrm{m}$ e $1 / 4 \mu \mathrm{m}$ e em politriz automática, utilizando sílica coloidal, durante $60 \mathrm{~min}$. Para exames por EBSD (método por difração de elétrons retroespalhados) foi realizada a mesma preparação para o MEV, acrescida do polimento manual com OP-S (Struers) e água, durante $20 \mathrm{~min}$. O tamanho de grão foi medido em analisador de imagens, determinando-se a área de cada grão e posteriormente extraindo a raiz quadrado do valor médio. Foram medidos pelo menos 100 grãos por amostra. Como complementação da análise do material, foram realizados testes de microdureza Vickers, com tempo de penetração de $10 \mathrm{~s}$, gerando o gráfico de microdurezas para as amostras recozidas em diferentes temperaturas. Com a finalidade de constatar o efeito do não recozimento intermediário sobre a estrutura e a textura do aço disponibilizado, compararam-se os resultados obtidos aos resultados de amostras que sofreram este recozimento. É importante ressaltar que o recozimento final (posterior à laminação a frio) de ambos os aços foi realizado em laboratório, utilizando as mesmas condições experimentais e equipamentos.

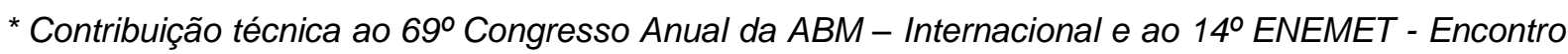
Nacional de Estudantes de Engenharia Metalúrgica, de Materiais e de Minas, 21 a 25 de julho de 2014, São Paulo, SP, Brasil.
} 


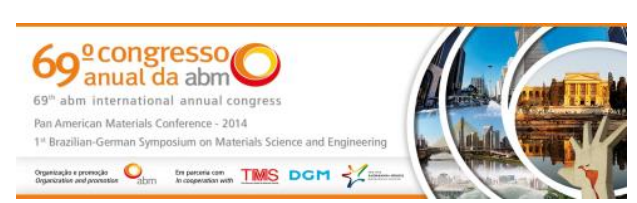

\section{RESULTADOS}

A fim de comparar a evolução da microestrutura e da textura do aço 430 estabilizado com nióbio, foi realizada a técnica de EBSD das amostras de aço laminada a quente (estado de fornecimento), encruado e recozido (nas temperaturas de $700^{\circ} \mathrm{C}, 750^{\circ} \mathrm{C}$, $800^{\circ} \mathrm{C}$ e $850^{\circ} \mathrm{C}$ ) e imagens de microscopia eletrônica de varredura (MEV). Para complementar a análise desta evolução, foi realizada também a construção do gráfico de microdureza Vickers e de fração amaciada em função da temperatura de recozimento.

\subsection{Microestrutura}

A Figura 1 ilustra a microestrutura das amostras laminada a quente-não recozida e laminada a quente-recozida no estado de fornecimento. Percebe-se claramente a diferença microestrutural, ou seja, o aço laminado a quente sem recozimento posterior apresenta grão alongados contendo bandas de deformação (Figura 1(a,c)), enquanto no aço recozido os grãos são poligonais (Figura 1(b,d)).

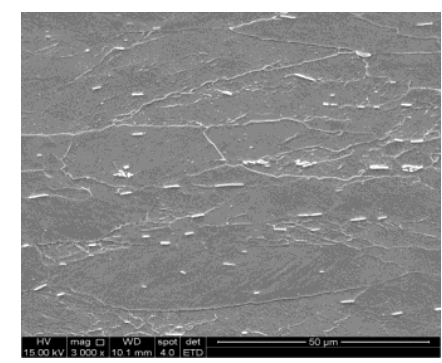

(a)

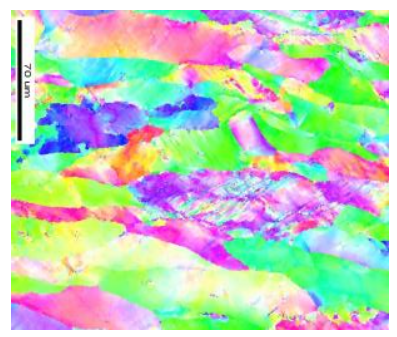

(c)

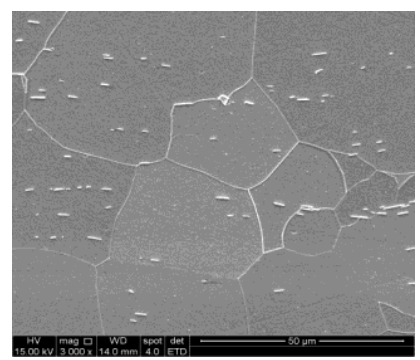

(b)

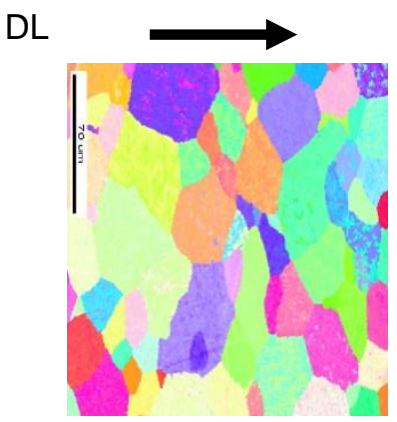

(d)

Figura 1 - Microestrutura das amostras conforme fornecidas; $(a, c)$ laminada a quente e não recozida e (b,d) laminada a quente e recozida. (a,b) Micrografias obtidas no MEV. (c,d) Mapas de orientação (inverse pole figure - IPF- figura de polo invertida) obtidos via EBSD com a direção de laminação (DL) na horizontal [11].

\subsubsection{Microscopia eletrônica de varredura}

Examinado as imagens do MEV obtidas, é possível observar que a amostra laminada a quente possui grãos achatados ou alongados e com mesma orientação em seus contornos. Após a realização da laminação a frio, a amostra encruada apresenta uma matriz alongada, enquanto as demais amostras, após recozimento, apresentaram modificação estrutural, recristalizando a partir da temperatura de $700^{\circ} \mathrm{C}$, concluindo tal recristalização na temperatura de $800^{\circ} \mathrm{C}$, onde se iniciou o crescimento de grãos. Além disso, é possível observar que as amostras que sofrem apenas um recozimento recristalizam mais rápido se comparadas com as amostras

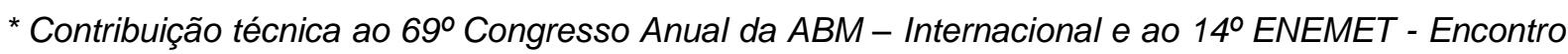
Nacional de Estudantes de Engenharia Metalúrgica, de Materiais e de Minas, 21 a 25 de julho de 2014, São Paulo, SP, Brasil. 


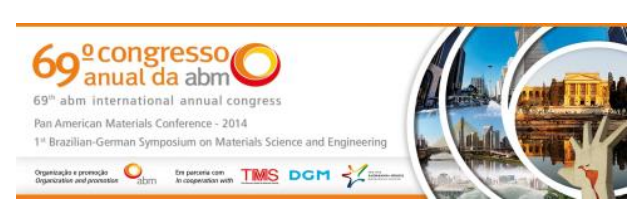

que sofrem dois recozimentos, devido ao acúmulo de energia armazenada ser maior.
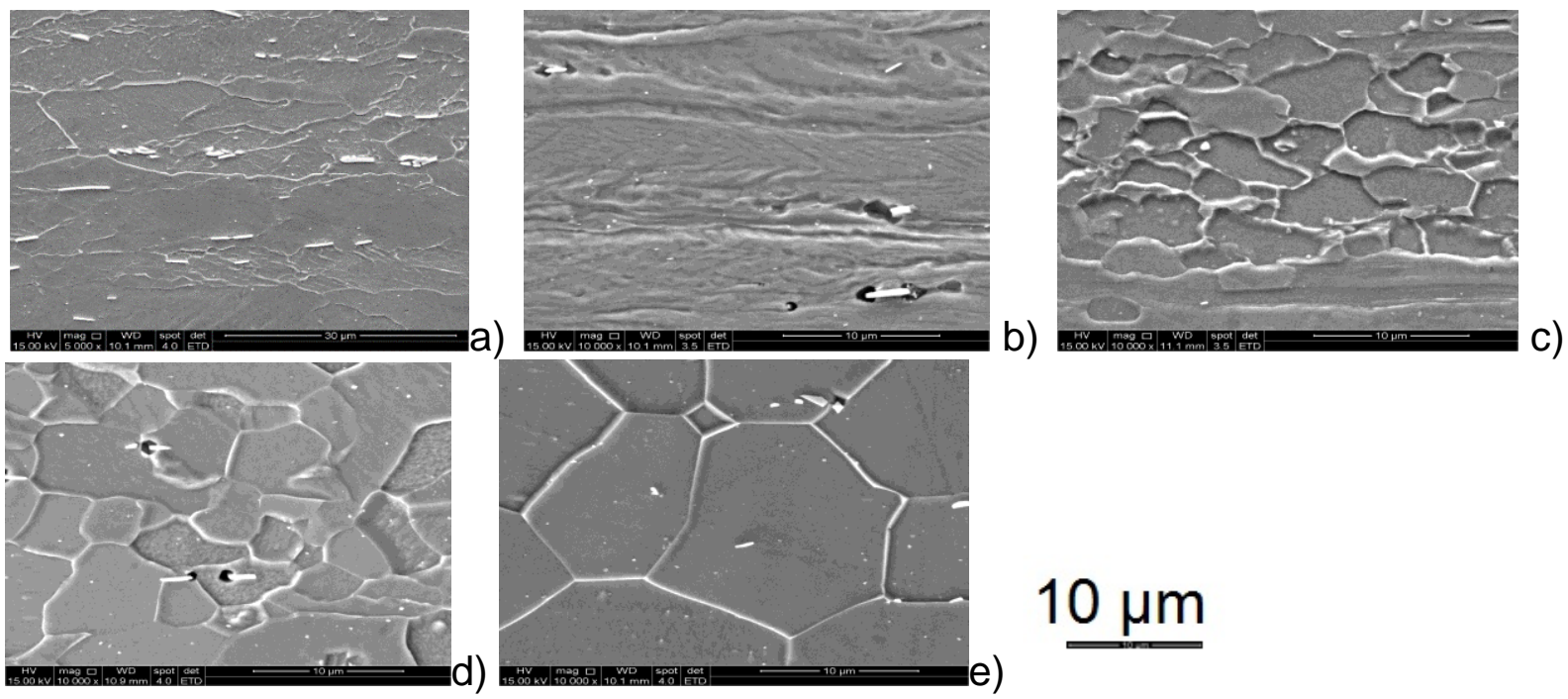

c)

Figura 1. Microestruturas de amostras do aço inoxidável 430E em (a) seu estado de fornecimento (laminado a quente) e (b) após laminação a frio, destacando seu estado encruado. Após recozimento nas temperaturas de (c) $700^{\circ} \mathrm{C}$, (d) $750^{\circ} \mathrm{C}$ e (e) $850^{\circ} \mathrm{C}$. Microscopia Eletrônica de Varredura, imagem de elétrons secundários.

Para efeito de comparação, foram utilizadas as imagens de microscopia eletrônica de varredura do aço 430E com recozimento intermediário [10].
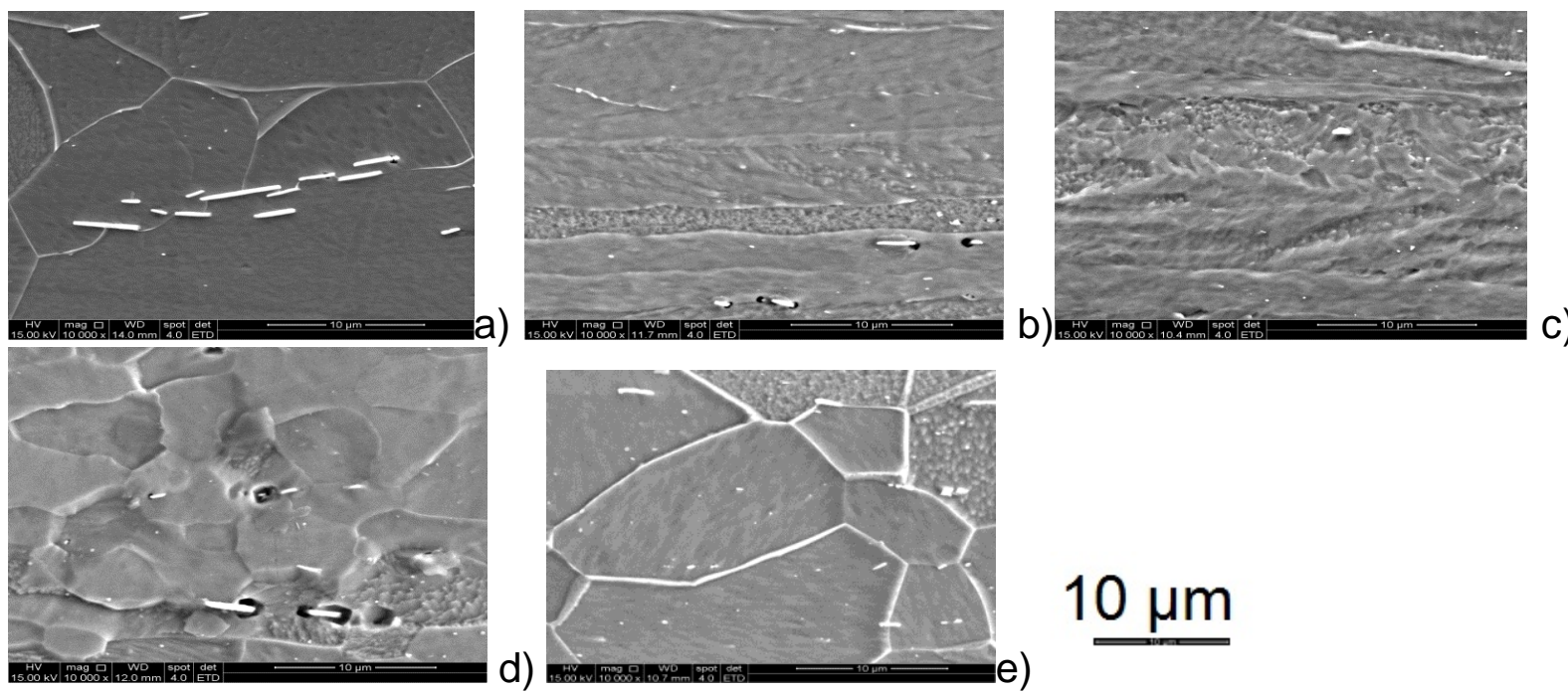

c)

Figura 2. Microestrutura das amostras do aço inoxidável 430E em (a) seu estado de fornecimento (laminado a quente e recozido) e (b) após laminação a frio, destacando seu estado encruado. Após recozimento nas temperaturas de (c) $700^{\circ} \mathrm{C}$, (d) $750^{\circ} \mathrm{C}$ e (e) $850^{\circ} \mathrm{C}$. Microscopia Eletrônica de Varredura, imagem de elétrons secundários.

É possível verificar a formação de grãos de ferrita na matriz das amostras recozidas após laminação a frio e o posterior crescimento destes grãos à medida que a recristalização progride. Devido a presença de carbonitretos de $\mathrm{Nb}$ na matriz do aço, ocorre o refinamento de grão em função do aumento dos sítios de nucleação na ferrita, nucleação estimulada por partículas (PSN) [2,7].

\footnotetext{
* Contribuição técnica ao 69 Congresso Anual da ABM - Internacional e ao 14ํㅡㄹ ENEMET - Encontro Nacional de Estudantes de Engenharia Metalúrgica, de Materiais e de Minas, 21 a 25 de julho de 2014, São Paulo, SP, Brasil.
} 


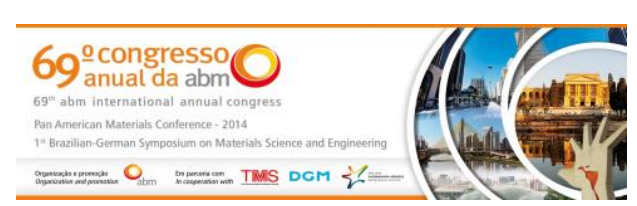

\subsubsection{Microdureza e fração amaciada}

Para uma análise mais precisa do momento em que se iniciou a recristalização, foram medidas as microdureza Vickers das amostras com e sem recozimento intermediário (Figura 3).



Figura 3. Microdureza Vickers em função da temperatura de recozimento para as amostras do aço $430 E$ não recozido e com recozimento intermediário.

Utilizando os dados de microdureza e no sentido de complementar a análise sobre o processo da recristalização das amostras com e sem recozimento intermediário, foi construído o gráfico da fração amaciada versus temperatura (Figura 4). Os dados obtidos para a construção do gráfico são provenientes da equação (1), em que XV é a porcentagem de fração amaciada, $H V_{e}$ é a dureza do material encruado, $H V_{r}$ é a dureza do material recristalizado e $\mathrm{HV}_{\mathrm{x}}$ é a dureza do aço na condição em questão (recozido em determinada temperatura). A evolução do tamanho de grão ferrítico com a temperatura de recozimento está ilustrada na Figura 5.

$$
\mathrm{XV}=\frac{H V_{e}-H V_{x}}{H V_{e}-H_{V r}}
$$

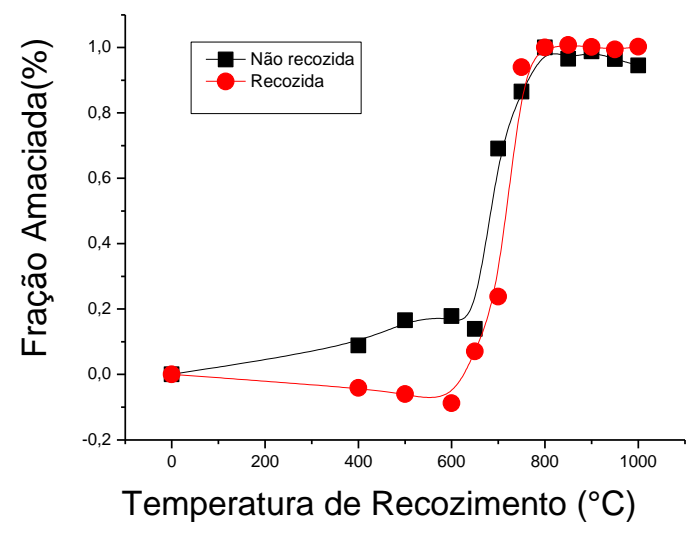

Figura 4. Fração amaciada em função da temperatura de recozimento para a amostra do aço 430E com e sem recozimento intermediário.

\footnotetext{
* Contribuição técnica ao 69ำ Congresso Anual da ABM - Internacional e ao 14ํㅡㄹ ENEMET - Encontro Nacional de Estudantes de Engenharia Metalúrgica, de Materiais e de Minas, 21 a 25 de julho de 2014, São Paulo, SP, Brasil.
} 

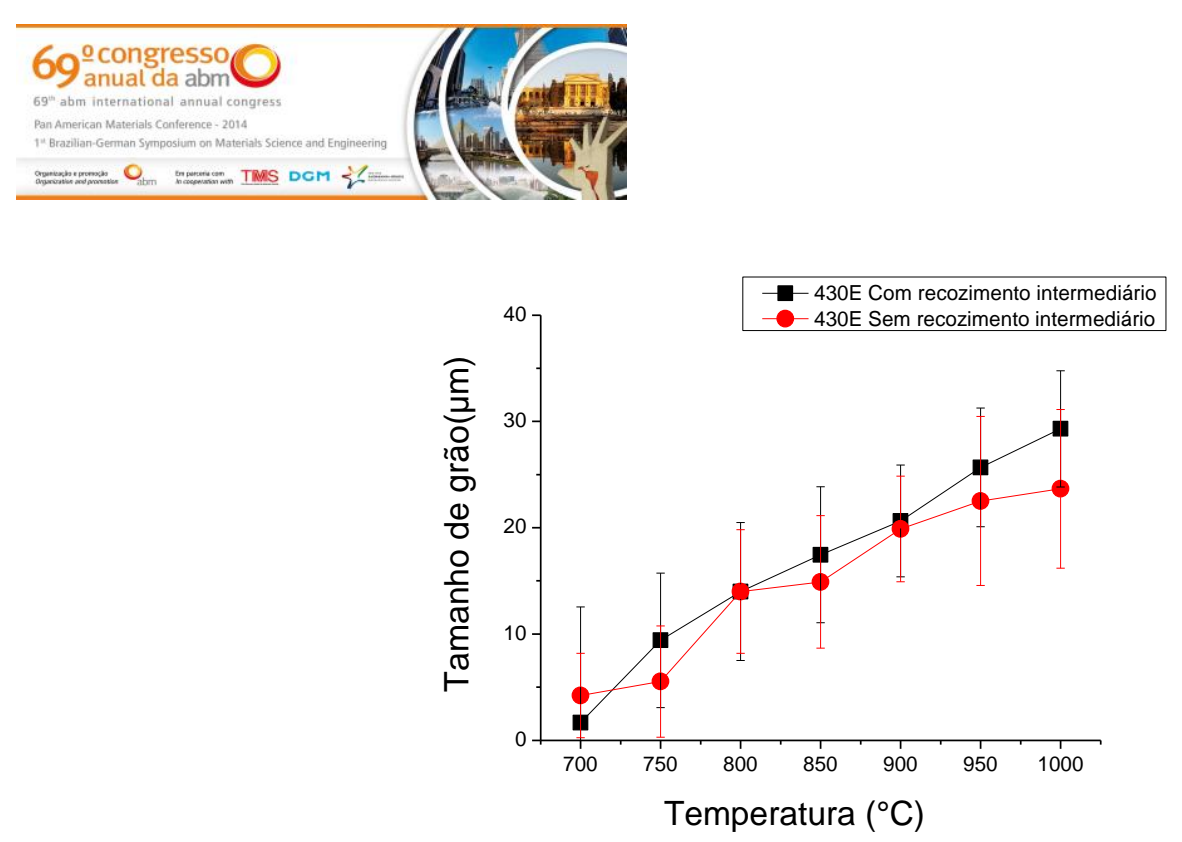

Figura 5. Tamanho de grão ferrítico em função da temperatura de recozimento para as amostras do aço $430 \mathrm{E}$ com e sem recozimento intermediário.

\subsection{Textura}

Foram analisadas as texturas cristalográficas das amostras que sofreram recozimento intermediário e das amostras que sofreram apenas o recozimento final após a laminação a frio, segundo o mapa de referência (Fig. 6). Examinando-se as figuras 7 e 8, onde são apresentadas as texturas (FDO - função de distribuição de orientação), nota-se que à medida que se aumenta a temperatura de recozimento e a consequente recristalização do aço, há um aumento na intensidade da fibra $\gamma\{111\}$ e diminuição da fibra $\alpha\langle 1-10\rangle$, corroborando com os dados encontrados na literatura $[1,5,9,12]$. Tal evolução da textura se dá pela redução das componentes $\{113\}<110>$ e $\{112\}<110>$ da fibra alfa, que tende, à medida que a temperatura de recozimento aumenta, para o aparecimento de componentes $\{111\}<121\rangle$ e $\{111\}<112>$ mais intensas, cofigurando a formação da fibra $\gamma$ citada.

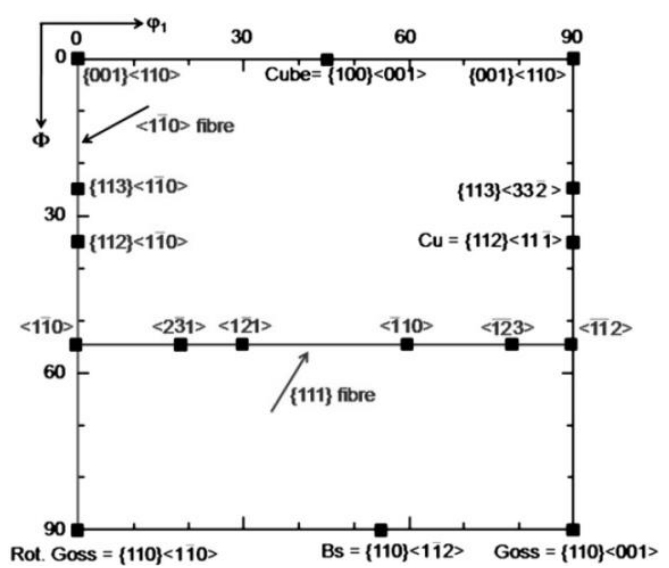

Figura 6. Mapa de referência para Texturas cristalográficas.

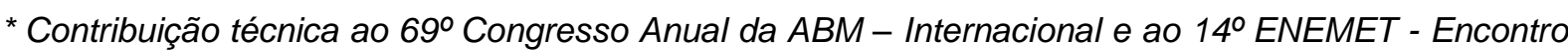
Nacional de Estudantes de Engenharia Metalúrgica, de Materiais e de Minas, 21 a 25 de julho de 2014, São Paulo, SP, Brasil.
} 

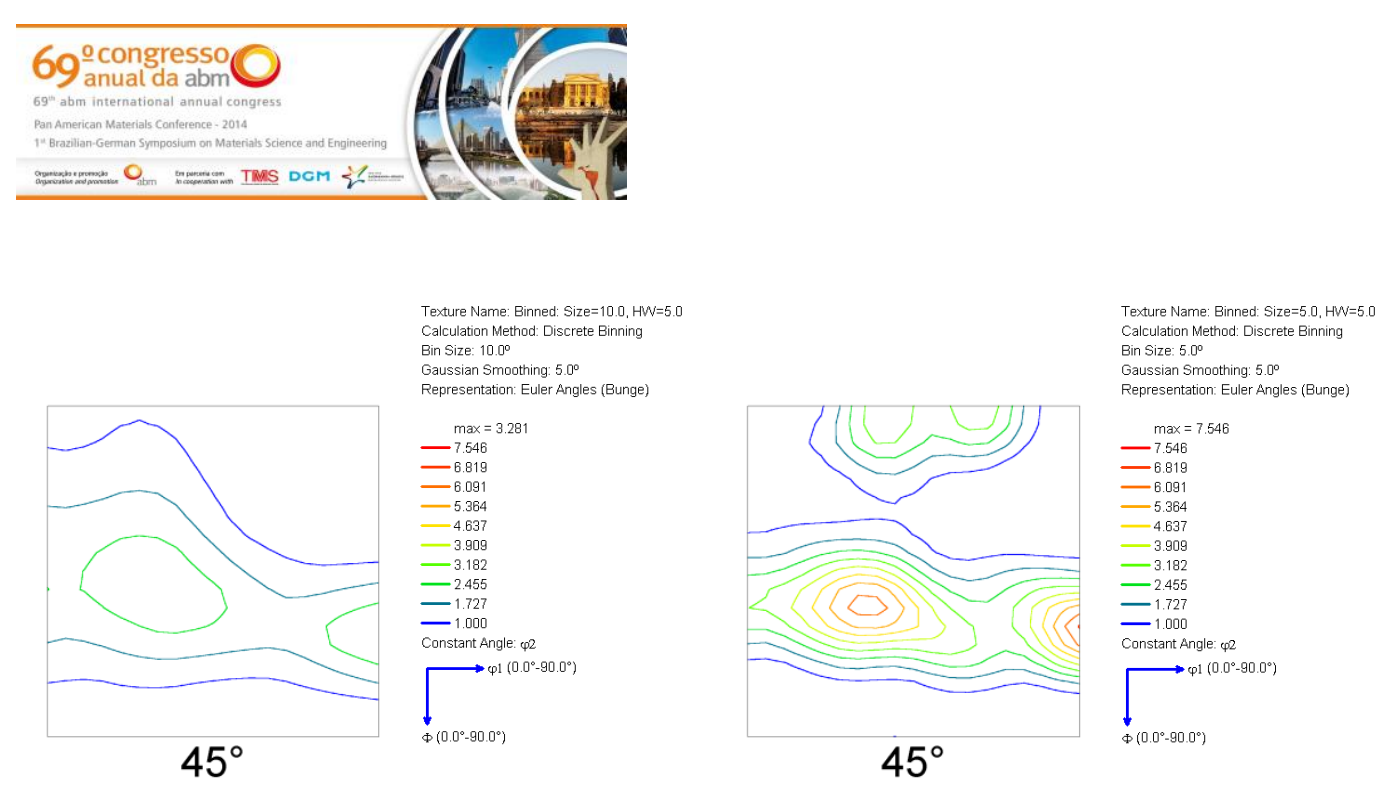

Figura 8. Texturas cristalográficas das amostras que sem recozimento intermediário e amostras que sofreram dois recozimentos, respectivamente, nas temperaturas de: (a) $700^{\circ} \mathrm{C}$, (b) $750^{\circ} \mathrm{C} \mathrm{e}$ (c) $850^{\circ} \mathrm{C}$.

\section{DISCUSSÃO}

À medida que a aço inoxidável 430 estabilizado com $\mathrm{Nb}$ foi recozido em temperaturas mais altas, pode-se perceber a formação de novos grãos de ferrita, que iniciam sua recristalização a partir da temperatura de $700^{\circ} \mathrm{C}$ e já se encontram completamente recristalizados quando o aço é recozido a $850^{\circ} \mathrm{C}$, como também é possível verificar pelo gráfico de microdureza Vickers (Figura 3). Devido à maior quantidade de energia armazenada na amostra recozida apenas uma vez, percebese que esta inicia sua recristalização antes da amostra que passou por dois recozimento. Esta maior nucleação na recristalização "prematura" permite que os grãos recristalizados se desenvolvam em uma maior fração volumétrica e sejam, portanto, mais refinados que aqueles existentes na amostra que se recristaliza posteriormente, ou em temperatura ligeiramente mais alta. Além disso, observa-se menor intensidade da fibra $\gamma$ nos mapas de orientação cristalográfica (Figuras 7,8 ).

Ainda, observando as imagens de microscopia eletrônica de varredura, bem como a curva de crescimento de grão (Figura 5), pode-se verificar um discreto refinamento dos grãos ferríticos na amostra que passou por somente um recozimento, tendo em vista a maior fração de energia desse material se comparado às amostras que sofreram dois recozimentos e, portanto, apresentam grãos maiores. Esses, por sua vez, começam a recristalizar em uma temperatura ligeiramente maior que o primeiro material citado.

Quanto à análise das texturas (Figuras 7 e 8) percebe-se uma diminuição da intensidade da fibra alfa, seguida de um aumento na intensidade da fibra gama.

De acordo com Raabe [12], a laminação a quente que o aço inox ferrítico é submetido resulta em aparecimento de fibras alfa e Goss, e uma fraca intensidade na fibra gama. Os grãos orientados em Goss tem como característica a instabilidade e, assim, com a laminação a frio, são girados na direção de formação de alfa ou gama. Isso explica o porque após laminação a frio há uma redução da fibra Goss, e um aumento da fibra alfa e gama (Figura 7(b)).

O aumento de dureza na respectiva curva da Figura 3 e um decréscimo até negativo na curva de fração amaciada (Figura 4) do aço com recozimento intermediário, deve-se, provavelmente, a presença de $\mathrm{Nb}$ em solução sólida após este recozimento, realizado na empresa de fornecimento. Segundo a literatura [6], a precipitação de carbonitretos de $\mathrm{Nb}$, em baixas temperaturas (no caso presente após o recozimento que seguiu a laminação frio, na temperatura de $600^{\circ} \mathrm{C}$ ) são

\footnotetext{
* Contribuição técnica ao 69ำ Congresso Anual da ABM - Internacional e ao 14ํㅡㄹ ENEMET - Encontro Nacional de Estudantes de Engenharia Metalúrgica, de Materiais e de Minas, 21 a 25 de julho de 2014, São Paulo, SP, Brasil.
} 


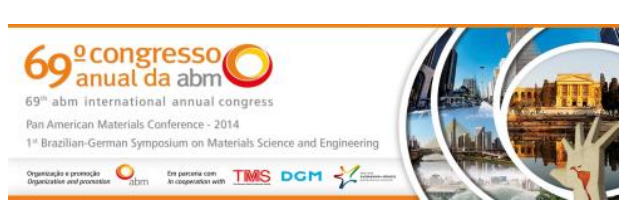

responsáveis por um aumento de resistência mecânica do aço na fase ferrítica. Quando não ocorre a solubilização parcial destes carbonitretos, isto é, o aço não passa pelo recozimento intermediário, promove-se uma redução gradual da dureza do aço ao longo dos recozimentos subsequentes, já que não há precipitação de partículas finas de $\mathrm{Nb}(\mathrm{C}, \mathrm{N})$ e, sim, somente a existência de partículas grosseiras (Figuras 1 e 2), que não exercem forte influência sobre a dureza do aço, podendose, assim, justificar o não aumento da microdureza e aumento na fração amaciada em temperaturas na faixa $400-600^{\circ} \mathrm{C}$ no aço sem recozimento intermediário. $\mathrm{O}$ mesmo fenômeno não ocorre para o aço com recozimento intermediário, justamente por haver uma solubilização parcial do elemento $\mathrm{Nb}$, decorrente do recozimento realizado na empresa em temperaturas acima de $1000^{\circ} \mathrm{C}$ [8].

Assim, como forma de reduzir os custos na empresa com a fabricação do aço $430 \mathrm{E}$ e a consequente otimização do tempo de fabricação do mesmo seria aconselhável a retirada do processo de recozimento intermediário, isto é, se as variáveis envolvidas forem somente as de laminação a frio e recozimento. Porém, uma resultante desse processamento é a formação da textura cristalográfica menos intensa na fibra $\gamma$ (Figura 8). Nessa direção, a abordagem do tema foi recentemente bem descrita por Oliveira et al. [8].

\section{CONCLUSÔES}

Com os exames e interpretação dos resultados desse trabalho foi possível concluir que o processo de recozimento influencia levemente no tamanho de grão das amostras de aço inoxidável ferrítico 430 estabilizado ao $\mathrm{Nb}$ e, portanto, não é o fator primordial atuante na recristalização das mesmas. Dessa forma pode-se dizer que os processos de deformação (laminação a quente e laminação a frio e o acréscimo de $\mathrm{Nb}$ à estrutura do aço) são muito mais relevantes que o recozimento intermediário quando se compara o aço que sofreu dois recozimentos com o que sofreu apenas um. Isso pode ser verificado pelo fato de os resultados de fração amaciada e microdureza não apresentarem diferenças significativas. Contudo, quando são comparadas as distribuições das componentes de textura cristalográfica, percebe-se a formação de uma fibra $\gamma$ mais intensa nas amostras que passaram pelo recozimento intermediário.

\section{Agradecimentos}

Os autores agradecem à CAPES e ao CNPq pelas bolsas de iniciação científica disponibilizada aos alunos de graduação. Também agradecem a empresa Aperam South America SA pelo fornecimento das amostras do aço inoxidável.

\section{REFERÊNCIAS}

1 Siqueira PR. Efeitos de orientação na recristalização do aço inoxidável ferrítico AISI 430 com grãos grosseiros e estabilizado ao nióbio. Tese de Doutorado.

Escola de Engenharia de Lorena da Universidade de São Paulo. 169 p.

2 Souza SA. Composíção Química dos Aços. Editora Edgard Blücher LTDA. Capítulo 3, página 45.

3 The Essential Guide to Ferritic Stainless Steels. The Ferritic Solution. Properties Advantages - Applications. International Stainless Steel Forum, 2007. 68 p.

\footnotetext{
* Contribuição técnica ao $69^{\circ}$ Congresso Anual da ABM - Internacional e ao 14ํㅡㄹ ENEMET - Encontro Nacional de Estudantes de Engenharia Metalúrgica, de Materiais e de Minas, 21 a 25 de julho de 2014, São Paulo, SP, Brasil.
} 


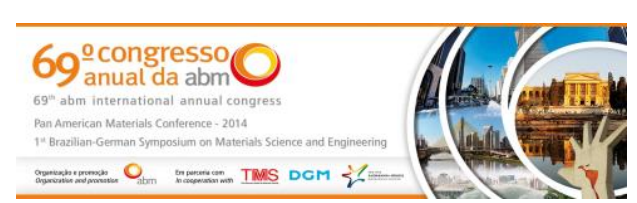

4 Oliveira TR. Effet du niobium et du titane sur la déformation à chaud d'aciers inoxydables ferritiques stabilisés. Tese de douturado. Ecole des Mines de Saint Etienne, França. 2003. 221 p.

5 Filho AF, Herrera C, Lima NB, Plaut RL, Padilha AF. Evolução da textura cristalográfica de chapas de aço inoxidável ferrítico do tipo AISI 430 durante laminação a frio, recozimento e estampagem. REM: Revista da Escola de Minas, 2008; 61(2): 151-158.

6 Deschamps A, Danoix F, Geuser F, Epicier T, Leitner H, Perez M. Low temperature precipitation kinetics of niobium nitride platelets in Fe. Materials Letters, 2011; 65: 2265 - 2268.

7 Padilha AF et al. Encruamento, recristalização, crescimento de grão e textura. 3‥ Ed. São Paulo: Associação Brasileira de Metalurgia e Materiais, p.12 - 55, 2005.

8 Oliveira TR, Silva RCR, Alcântara CM, Lopes RG, Ferreira JS, Arthuso EM. et al. Aço Inoxidável Ferrítico tipo ASTM 430 para estampagem profunda, com alto brilho e isento de estriamento. $68^{\circ}$ Congresso Anual da Associação Brasileira de Metalurgia, Minas e Materiais - ABM, Julho 2013, Belo Horizonte, Brasil. p. 22402250.

9 Yan $\mathrm{H}, \mathrm{Bi} \mathrm{H}, \mathrm{Li} \mathrm{X}, \mathrm{Xu} \mathrm{Z}$. Effect of two-step cold rolling and annealing on texture, grain boundary character distribution and $\mathrm{r}$-value of $\mathrm{Nb}+\mathrm{Ti}$ stabilized ferritic stainless steel. Materials Characterization, 2009; 60: 65-68.

10 Siqueira RP, Sandim HRZ, Oliveira TR, Raabe D. Composition and orientation effects on the final recrystallization texture of coarse-grained $\mathrm{Nb}$-containing AISI 430 ferritic stainless steels. Materials Science and Engineering A, 2011, 528: 3513-3519.

11 Cunha AF, Carmo DCD, Campos RO, Santos DB, Barbosa R. Evolução da Microestrutura do Aço Inoxidável Ferrítico AISI 430 Estabilizado com Nióbio Laminado a Frio e Submetido a Recozimentos Isócronos. 50․ Seminário de Laminação 2013 - ABM, Ouro Preto, MG. p. 348-358.

12 Raabe $\mathrm{D}$. On the influence of the chromium content on the evolution of rolling textures in ferritic stainless steels, Journal of Materials Science, 1996; $31: 3839$ 3845 .

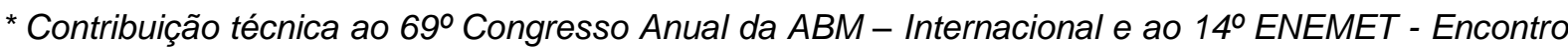
Nacional de Estudantes de Engenharia Metalúrgica, de Materiais e de Minas, 21 a 25 de julho de 2014, São Paulo, SP, Brasil. 